\title{
Gaurishankar Conservation Area - A Prime Habitat for Red Panda (Ailurus fulgens) in Central Nepal
}

\author{
Arjun Thapa ${ }^{1}$ Sunil Thapa ${ }^{1}$ and Shambu Poudel ${ }^{2}$ \\ Corresponding email: thapa.nature@gmail.com
}

\begin{abstract}
:
Globally threatened Red Panda is found in isolated high mountain's bamboo-forest patches in Nepal, India, Bhutan, China and Burma. This study was focused in Gaurishankar Conservation Area, one of the newly declared protected areas of Nepal, with aim to glean baseline information regarding existence of Red Panda, its habitat status and conservation issues. Methods like altitudinal line intercept, key informant survey and consultation (with local people, herders, conservation stakeholder) were used to address the objectives. Marbu, Kalinchok, Gaurishankar (Dolkha District), Chuchure, Gumdel (Ramechhap District) and Fulpingkatti (Sindupalchok District) area were surveyed in first phase of study and presence of Red Panda distribution was recorded from Marbu, Kalinchok, Chuchure and Fulpingkatti forests areas through sign evidence (fecal pellets). A total of 24 transects were established randomly in the whole area and only 16 transects were worked effectively because of topographical barrier. Distribution of Red Panda was found as clumped pattern (). Among these sites, frequent sign encounter was recorded in Marbu $(5.45 / \mathrm{km})$ area followed by Fulpingkatti $(5.06 / \mathrm{km})$, Kalinchok $(3.73 / \mathrm{km})$ and Chuchre $(1.67 / \mathrm{km})$. Like in other areas, conservation issues like habitat destruction, livestock pressure, fire wood collection and illegal poaching were rampant in Gaurishankar also. This study recommended for detail survey on population status and conservation activities should be elaborated in current identified habitat as well as further survey should be focused on other possible habitats within conservation area.
\end{abstract}

Key Words: Distribution, Fecal pellets, Gaurishankar Conservaton Area, Red Panda, Transect

\section{Introduction}

Nepal's high priority in biodiversity conservation is reflected in the increasing number of protected areas which covers more than $20 \%$ of the total area of the country. In fact, such creation process plays significant role in biodiversity, results in protection and conservation

${ }^{1}$ Small Mammals Conservation and Research Foundation

2 Assistant lecture, Kathmandu Forestry College, Balkumari, Kathmandu 
of endangered and rare species. Recently, Government of Nepal proclaimed Gaurishankar Conservation Area (GCA) as new conservation area, that appended a protected area in Sacred Himalayan Landscap (SHL) and extends in three districts comprising six VDCs (Gumba, Tatopani, Listikot, Fulpingkatti, Marming, and Ghorthali) of Sindhupalchok district, fourteen VDCs (Kalinchok, Bigu, Alampu, Chilankha, Lambagar, Orang, Bulung, Laduk, Gaurishankar, Khare, Marbu, Chankhu, Suri, and Syama) of Dolakha district and Chuchure and Gumdel VDCs of Ramechhap district with an area of about $2179 \mathrm{~km}^{2}$. It lies between the Langtang National Park in the West and the Sagarmatha National Park in the east and thus act as biological corridor for large home range high altitude's fauna.

The Red Panda (Ailurus fulgens) is recorded in isolated pockets of high mountain ranges in western China (Sichuan, Yunnan and Tibet provinces) and the Himalayan mountain chain of Nepal, India, Bhutan and Burma, with a separate population on the Meghalaya Plateau in north-eastern India (Roberts and Gittleman, 1984; Glatston, 1994; Wei et. al., 1999; Yonzon, 1989; Reid et al., 1991 and Pradhan et al., 2001). The global population of the Red Panda is estimated at 16000 to 20000 individuals based on ecological density (Choudhary, 2001). Now its population is estimatedat 10,000 in wild (IUCN, 2008). Nepal hosts about $1.9 \%$ of the total global population of the Red Panda and estimated 314 individuals based on habitat suitability (Yonzonet al., 1997). Population of Red Panda is declining day by day from its viable habitat of the world and IUCN has mandated it as endangered species since 1996 but now it is listed under Vulnerable category (IUCN, 2008) and also legally protected by Government of Nepal under Schedule I (section 10) of National Parks and Wildlife Conservation Act 2029 (1973). PAs network of Nepal cover about 20\% of the total area, but more than $62 \%$ of the Red Panda potential habitat remains outside the protected areas which may have higher risk due to human pressure (Yonzon et al., 1997), still research works are concentrated within protected areas only (Yonzon, 1989; Mahato, 2004; Sharma, 2008; Thapa, 2009 and Kandel, 2009). This study aimed to glean base line information of Red Panda; its distribution and conservation issues.

\section{Material and Methods}

\section{Study Area}

Newly designed Gaurishankar Conservation Area (85047.4' and 86 $34.8^{\prime}$ 'East longitude and $27^{\circ} 34.2^{\prime}$ 'and $28^{\circ} 10^{\prime}$ North Latitude) was gazette in July 19, 2010 that fall under Sacred Himalayan landscape. GCA harbor rich floral and faunal diversity along with cultural significance. Varied physiography and climatic condition provides the
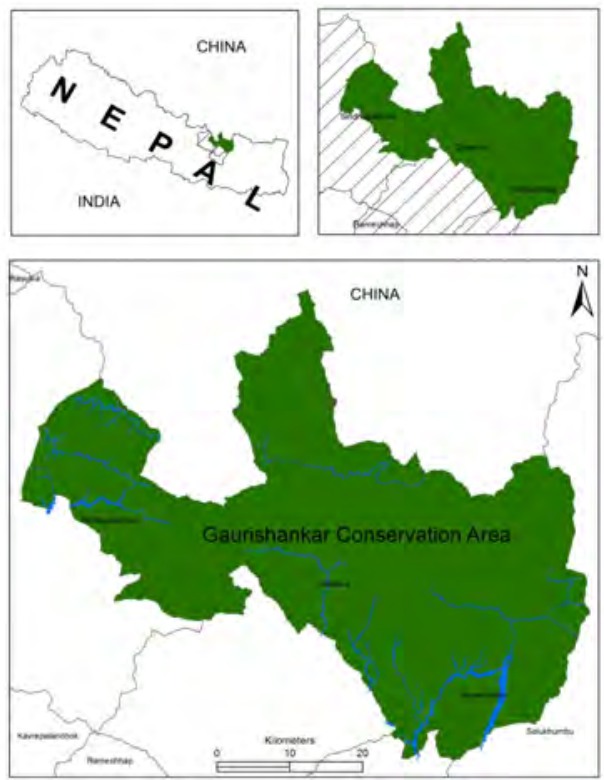

Figure 1: Map of Study area 
existence of diversified vegetation composition viz. subtropical forest (Pine forest, SchimaCastonopsis forest etc.) to alpine shrub land. In addition, agricultural lands, human settlements, cliffs and aquatic habitats are also present. This conservation area act as refuge for more than 34 mammals species including globally concern species like Red Panda, Snow leopard along with other bird, herpeto-fauna and fishes (NTNC, 2009).

\section{Methods}

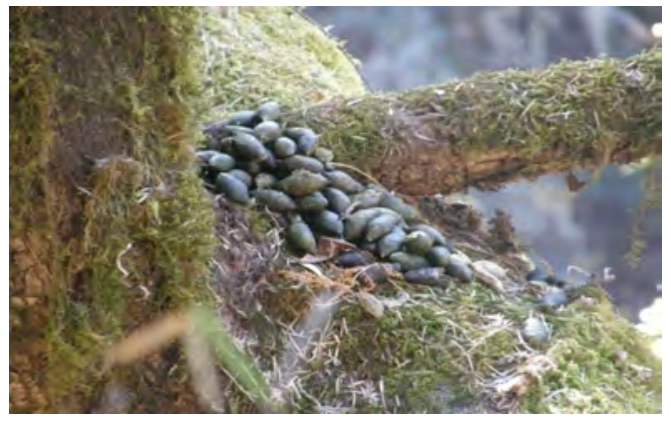

Figure 2: Fecal pellet of Red Panda in three branches

Field survey was carried out in the months of July, 2011. During this period, altitudinal line intercept method was used for sign (fecal pellet, pugmark) survey. As well as other potential Red Panda habitats and conservation issues were identified from the secondary sources, literatures, semi structural questionnaires and informal interviews with local villagers, herders, conservation hotel staffs near the study areas. Fecal pellet is an effective indicator for sign survey of Red Panda due to their shy nature. The recognized probable habitat of animal in conservation area was surveyed following Williams (2004), Mahato (2004) and Kandel (2009). Horizontal transects were laid in each block along contour lines between elevations of $2600 \mathrm{~m}$ and $3600 \mathrm{~m}$ with an altitudinal spacing by 200m. In transects, signs encountered were recorded keeping limitation on transect lengths due to varied topography (cliff, steep, rocky, river etc) and distribution pattern of animal was carried following the Odum (1971).

\section{Results and Discussion}

This Field survey was carried out in 2011 that validated the presence of Red Panda in newly declared Gaurishankar Conservation Area. Based on sign survey (fecal pellet/ droppings) presence of Red Panda was recorded in Marbu and Kalinchok (Dolkha), Chuchure (Ramechhap) and Fupingkatti (Sindupalchok).

Similarly, study was carried in Sema Village of Garurishankar VDC and Gumdel areas of Ramechhap, where sign was not recorded in the survey transects; however vegetation of habitat as well as key information survey (local voice) support the high possibility in existence of Red Panda. Results of key information survey (KIS) and consultation with local level conservation
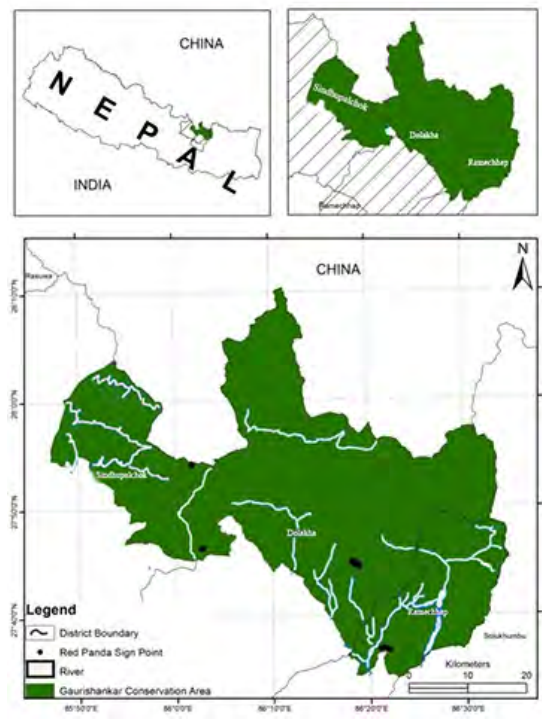

Figure 3: Distribution of Red Panda presence in GCA 
stakeholder also urge other areas like Tatopani, Bigu and Ghorthali for Red Panda presence. There wasn't any record of Red Panda signs in elevation below $3000 \mathrm{~m}$ in four confirmed areas.Fecal pellets were encounter above $3000 \mathrm{~m}$ in Marbu and Fulpingkatti; whereas it was recorded around $3200 \mathrm{~m}$ elevation in Fulpingkatti and Chuchure areas. There was no visual encounter of animal during transects survey. Current study showed

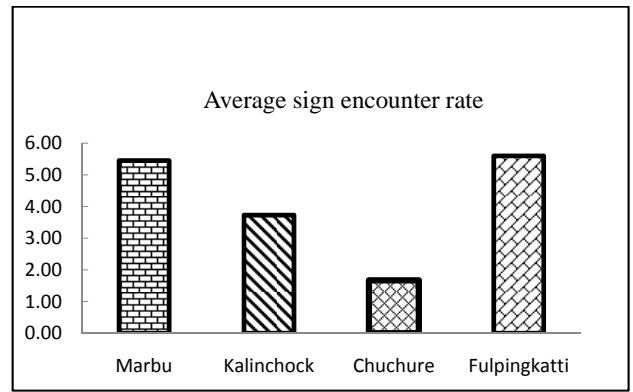

Figure 4: Average sign encounter rate in sites that distribution of Red Panda varies within range between $3000 \mathrm{~m}$ to $3600 \mathrm{~m}$. This study indicated the clumped pattern of distribution $\left(S^{2} / \bar{X}=3.06>1, x^{2}=0.445, P<0.05\right.$ $S^{2} / \bar{X}=3.06>1, x^{2}=0.445, P<0.05$ ) in GCA that supported the study carried from Illam (Kandel 2009), Dhorpatan Hunting Reserve (Subedi 2009 and Kandel 2009). Though study carried in Buffer Zone of Sagarmatha National park found distribution of Red Panda in patches separated by steep terrains (Mahato 2004). In nature, clumped pattern of distribution is more frequent in comparison to other types of distribution ie. random and uniform.

\section{Threats and Conservation issues}

Threats to the Red Panda were determined by considering the livestock and human pressure. In the intensive study area, livestock was dominated by Chauri and grazing was prevalent in all sites. Seasonally, large herds of livestock were grazed in different pastures near all four study sites where livestock spend about six to seven months that possesses higher pressure to the Red Panda. Along with this, livestock and herder, dogs used to visit Red Panda habitat frequently which has

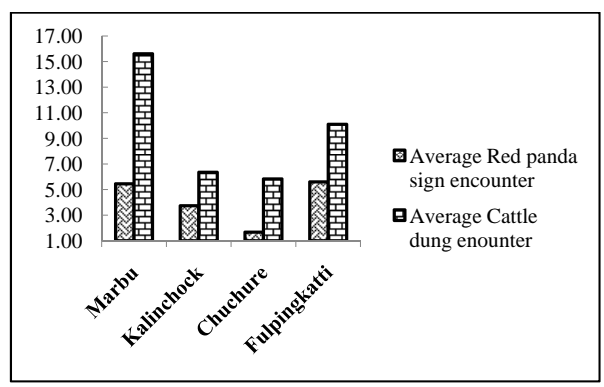

Figure 5: Average Red Panda sign encounter and average cattle dung encounter in the four areas chances of killing Red Panda. In Marbu, average cattle dung encounter is high compared to other areas that disturb Red Panda habitat. About 16 cattle sheds (Goths) were counted in Marbu with average 18 Chauri per shed. There are cheese processing unit (government/ private), that encouraged herders to increase their livestock number by providing them soft loan and reasonable price for milk. This activates also support for high grazing stress.

Along with grazing; fire collection, fodder collection, malingo and shoots of malingo (bamboo shoot) collection were issues of threats to the animal. Interviews suggested that local people used bamboo and shoots for various purposes such as for making basket and rooftop, as fodder, and fencing and bamboo shoots were used as vegetables and pickle. 
They also used these shoots to feed their livestock as cattle feed. Hunting doesn't appear to be a serious threat as habitat loss, overgrazing and fire wood collection. During the study period, hunting evidences was found in cattle sheds in the Marbu area but was not recorded from other study sites.

\section{Conclusion}

Presence of Red Panda was confirmed in Gaurishankar Conservation Area (GCA) and showed the patchy distribution. Sign evidence (droppings) indicated existence of Red Panda from four areas; Marbu and Kalinchok (Dolkha), Chuchure (Ramechhap) and Fulpingkatti (Sindupalchok). Signs of Red Panda were encountered at the elevation of $3000 \mathrm{~m}$ from surveyed areas and gradually scared at elevation $3600 \mathrm{~m}$. This study indicated

the clumped pattern of distribution $\left(S^{2} / \bar{X}=3.06>1, x^{2}=0.445, P<0.05\right.$ $S^{2} / \bar{X}=3.06>1, x^{2}=0.445, P<0.05$ ) in GCA. A total of 24 transect were laid, among them 16 transect were effective for Red Panda sign encounter. Marbu showed the highest sign encounter rate followed by Fulpingkatti, Kalinchock and Chuchure. Particularly, the droppings were found in tree and ground.

The Red Panda in study area is facing problems of habitat destruction, livestock pressure, fire wood collection, fodder collection as well as illegal poaching. Likewise, grazing of cattle in the Panda habitat and use of bamboos as vegetables, roofing materials and as other raw materials for domestic utensils are also the indirect threats to Red Pandas.

\section{Acknowledgements}

I would like to express my sincere thanks to Rufford Small Grant Program UK, National Trust for Nature Conservation (NTNC) and North England Zoological Society, UK for providing financial support. Small Mammals Conservation and Research Foundation (SMCRF) for providing field equipments as well as World Association Zoo and Aquariums (WAZA) for project branding. My cordial thank goes to Dr. Shanta Raj Janwali, Mr. Satya Narayan Shah, PrakashBhattarai, Kamal Nepali,NavarajChapagainBabu Ram Lamichani, MadanSulwal, Bed Prasad Bhurtel, SubarnBasnet, Ramesh Silwalfor their kind help during different phases of work.

\section{References}

Choudhury, A.U. 2001. An overview of the status and conservation of the Red Panda in India, with reference to its global status. Oryx, 35: 250-259.

Glatston, A.R. 1994. The Red Panda, olingos, coatis, raccoons, and their relatives. Status survey and conservation action plan for procyonids and ailurids. IUCN/SSC mustelid, viverid and procyoni specialist group.IUCN, Gland, Switzerland. 
IUCN. 2008. IUCN Red List of Threatened Species.

[http://www.iucnredlist.org].Downloaded on 20 September, 2011.

Kandel, K. 2009. Distribution and habitat use of Red Panda (Ailurus fulgens) in eastern Nepal. Nepal. M.Sc. Thesis. Central Department of Zoology, Tribhuvan University, Kirtipur, Nepal 44 pp.

Mahato, N. K. 2004. Report of the baseline survey of Red Panda (Ailurus fulgens) status in the buffer zone of Sagarmatha National Park. WWF Nepal program, Kathmandu, Nepal, 23 pp.

NTNC. 2009. Report of the scoping study to develop Gaurishankar into a protected area. National Trust For Nature Conservation, Jawalakhel, Lalitpur, xiv-100 pp.

Odum, E. P. 1971. Fundamentals of Ecology. W.B. Saunders Company, USA. 574pp.

Pradhan, S., Saha, G. K. \& Khan, J. A. 2001. Ecology of the Red Panda (Ailurus fulgens) in the Singhalia National Park, Darjeeling, India.Biological Conservation 98: 11-18.

Pradhan, S., Saha, G. K. \& Khan, J. A. 2001. Food habits of the Red Panda (Ailurus fulgens) in the Singhalia National Park, Darjeeling, India. Journal of Bombay Natural History Society 98(2): 224-230.

Reid, D. G., Jinchu, H. \& Hunang, Y. 1991. Ecology of the Red Panda (Ailurus fulgens) in the Woolong Reserve, China.Journal of Zoology 225:345-364.

Roberts, M. \& Gittleman, J. 1984. Ailurus fulgens.Mammalian Species 222: 1-8.

Sharma, H. P. 2008. Report of the distribution of Red Panda (Ailurus fulgens) in Rara National park, Nepal. People’s Trust for Endangered Species, London.

Stainton, J.D.A. 1972. Forest of Nepal.John Murray, Camelot Press Ltd., London.

Subedi, T. R. 2009. Report of the habitat, status and conservation of Red Panda (Ailurus fulgens) in Dhorpatan Hunting Reserve, Nepal.Rufford Small Grant Foundation, UK.

Thapa, A. 2010. An analysis of food habits and conservation of Red Panda Ailurus fulgens in Langtang National Park. M.Sc. Thesis. Central Department of Zoology, Tribhuvan University, Kirtipur, Nepal, 44pp.

Wei, F.W., Feng, Z. J., Wang, Z.W. \& Hu., J.W. 1999. Current distribution, status, and conservation of wild Red Pandas (Ailurus fulgens) in China.Biological

Conservation, 89(3): 285-291. 
Williams, B. H. 2004. The Status of Red Panda in Jamuna and Mabu Villages of Eastern Nepal. M. Sc. San Jose state University, USA, xvii-194 pp.

Yonzon, P. B. 1989. Ecology and conservation of the Red Panda in the Nepal-Himalayas.

Ph. D. Dissertation. University of Maine, USA, 195 pp.

Yonzon, P. B., Yonzon, P., Chaudhary, C. \& Vaidya, V. 1997. A report of status of the Red Panda in the Himalaya.Resources Nepal, Kathmandu and Metropolitan Toronto Zoo Project, Toronto, Canada, 21pp 